\title{
O MÉTODO MATERIALISTA HISTÓRICO E DIALÉTICO PARA A PESQUISA EM EDUCAÇÃO
}

\author{
Marília Freitas de Campos Tozoni-Reis ${ }^{1}$
}

\begin{abstract}
Resumo
Este estudo apresenta o Método Materialista Histórico e Dialético como uma das abordagens possíveis de interpretação da realidade social, e, por consequência, da realidade educacional. A construção lógica deste Método, que fundamenta o pensamento marxista, apresenta-se como possibilidade teórica (instrumento lógico) e metodológica (orientando caminhos) de interpretação dessa realidade. Essa abordagem metodológica caracteriza-se pelo movimento do pensamento pela materialidade histórica da vida dos homens em sociedade, isto é, trata-se de descobrir (pelo movimento do pensamento) as leis fundamentais que definem a forma organizativa que a humanidade historicamente construiu para seus grupos sociais. Como instrumento de reflexão teórico/prática o Método pode colocar a realidade educacional aparente em análise para que seja, pelos educadores, plenamente compreendida e superada, tornando-se, então, realidade educacional concreta, pensada, interpretada em seus mais diversos e contraditórios aspectos para que, numa escolha política mais consciente e consequente, possa ser transformada.
\end{abstract}

Palavras-chave: educação; marxismo; modelos teóricos

\section{Introdução}

Escrevi sobre o Método do Materalismo Histórico e Dialético para a Educação já há algum tempo, em 1997 (Pires, 1997), tanto tempo que meu último sobrenome ainda era outro! Um convite para participação como palestrante do tema no II SIMPÓSIO: MATERIALISMO HISTÓRICO DIALÉTICO E PESQUISA EM ENSINO DE CIÊNCIAS E EDUCAÇÃO AMBIENTAL em 17/05/2019 para uma palestra sobre o tema, me deu oportunidade de retomar aquele texto, revisitando-o, revendo-o e ampliando-o. Mas, é preciso dizer que em nenhum momento desde então me afastei do Método, tanto em seu estudo quanto em minhas atividades de ensino, pesquisa e extensão na Universidade, mas também, e tão rigorosamente quanto, em minha vida cotidiana. Isso porque este Método, muito mais do que um conjunto de técnicas de procedimentos na pesquisa acadêmica, é uma teoria, um conjunto de conhecimentos que se constituem numa rica e vigorosa orientação na interpretação da realidade em que vivemos, seja a realidade educacional, social, histórica, econômica, ambiental, mas também todas as demais dimensões da vida que nos exigem mais do que uma compreensão imediata, empírica, da realidade, que nos exige uma compreensão mais 
profunda, plenamente compreendida, uma compreensão concreta da realidade. E, se pensarmos também que esse Método foi desenvolvido para a compreensão crítica das relações sociais sob o modo capitalista de produção, é instrumental teórico/prático de transformação dessas relações.

Assim, iniciemos pela consideração de que a busca de teorias que orientem a interpretação da realidade para o pensar e agir nos processos educacionais - tarefa filosófica da maior importância para educadores em formação, inclusive nos cursos de pós-graduação como o do evento que deu origem a este texto - exige a compreensão de como nós, humanos, nos relacionamos: como os humanos se relacionam entre si, com as coisas, com a natureza, enfim, com a vida. Ocorre que este problema filosófico central em todas as ciências é compreendido por elas a partir de diferentes abordagens, de diferentes teorias, de diferentes "paradigmas" e esta é a tarefa central da epistemologia. Ou seja, nós pesquisadores em educação - formados e em formação -, assim como todos os demais educadores e também pesquisadores de todas as áreas do conhecimento, para avançarmos na compreensão dos nossos temas e objetos de estudo necessitamos conhecer e nos aprofundar na compreensão epistemológica de nossos campos e áreas de estudo.

Isso significa dizer que é preciso que os educadores, e consequentemente os pesquisadores em Educação, ao se dedicarem ao estudo e à ação educativa, tenham conhecimento da natureza de sua área e campo de estudo. A epistemologia é, portanto, a teoria do conhecimento, a teoria do conhecimento de nossas áreas e campos de estudo. Como uma das principais áreas da filosofia, a epistemologia dedica-se ao estudo da origem do conhecimento, mas compreende também, e principalmente, as possibilidades do conhecimento, ou seja, as possibilidades de alcançarmos o conhecimento mais completo possível em nossas atividades de estudo e pesquisa. A epistemologia é, portanto, a própria filosofia da ciência. Se o conhecimento nos "informa" sobre o mundo natural e social - o que chamamos de "realidade" - portanto, é esse conhecimento que nos orienta na interpretação dessa realidade. Ou seja, se buscamos em nossas áreas e campos de estudo produzir conhecimentos que nos garantam nesta interpretação do mundo natural e social de forma mais aprofundada do que a experiência empírica imediata, precisamos de métodos - teorias - que nos orientem na interpretação do mundo. E é neste sentido que apresento neste texto um determinado Método - teoria.

Mas, antes disso, vejamos quais necessidades epistemológicas - teóricas -, me fizeram chegar a este determinado Método. 
Minha formação inicial na educação no curso de Pedagogia, por circunstâncias pessoais, foi bastante incipiente. Mas, iniciada minhas atividades como professora de educação infantil, a busca por uma melhor formação - formal e não formal - me levou a estudos mais elaborados que culminaram em meu ingresso na Universidade como professora de um curso de Pedagogia. Então, a definição da pré-escola pública como preocupação central de meu trabalho nesse curso, o que significava compreendê-la em sua dimensão política, foi um processo de superação do tratamento que eu vinha dando à educação infantil. No início de meus estudos, influenciada pela prática educativa em pré-escolas privadas, focava minha atenção nos aspectos cognitivos desta prática, sobre as concepções acerca do desenvolvimento cognitivo das crianças. Essa abordagem cognitiva, no entanto, não conseguia explicar a importância do caráter social e histórico do desenvolvimento humano e da educação, exigindo aprofundamento na compreensão dos aspectos políticos e sociais da educação das crianças pequenas. $\mathrm{O}$ enfoque biológico sobre o histórico e social mostrava-me as dificuldades dessas abordagens no pensar e agir educativo em defesa do direito à educação infantil das crianças da então pré-escola pública.

O aprofundamento destas reflexões pelas leituras sobre educação e educação infantil com enfoque filosófico-político contribuíram para que eu pensasse a educação infantil inserida na contraditória política educacional brasileira. Isso exigiu estudos acerca dos aspectos políticos, econômicos e sociais da organização da sociedade brasileira, sobre política educacional, e sobre política da então educação pré-escolar mais especificamente. Foi intenso e produtivo esse momento de reflexão teórico-prática: a história, a filosofia, a sociologia, (e um pouco de economia política) e a política educacional passaram a ser as áreas subsidiárias dos estudos em educação infantil. Também não me satisfazia a orientação empirista de compreensão da educação infantil na escola pública dado sua impossibilidade de explicar sua estrutura e funcionamento em uma sociedade marcada por tão grandes e profundas desigualdades. Muitos estudos sobre política educacional, orientados por essa abordagem empirista não dão conta dessa explicação, pois referem-se, em geral a uma realidade aparente, imediata, que se preocupa em quantificar fenômenos educativos sem tentar compreendê-los em sua profundidade.

Dessa forma, um contato mais intenso e disciplinado com o Método Materialista Histórico e Dialético como Método de interpretação da realidade durante o curso de pósgraduação tornou-se referencial teórico para minha prática educativa pela forma com que ele permite a compreensão mais aprofundada da educação inserida na contraditória sociedade de classes em que vivemos. As categorias do concreto, concreto histórico e concreto histórico 
e dialético foram tomadas como referências teóricas e epistemológicas na compreensão da educação voltada aos interesses e necessidades das camadas mais pobres da população.

Diante disso, o que é o Método Materialista Histórico e Dialético como referencial teórico e metodológico para a pesquisa em educação?

\section{O Método}

Iniciemos aqui pela consideração de que nossa atuação na educação, como professores e pesquisadores, nos coloca a necessidade de conhecer os mais variados elementos que envolvem a prática educativa, isto é, temos a necessidade de compreender a educação e o ensino da forma mais completa possível. Para isso, precisamos de um Método, um caminho que permita, filosófica e cientificamente, compreender a educação. E, se a lógica formal foi se mostrando insuficiente para esta tarefa, parece possível buscar, no Método Materialista Histórico e Dialético, este caminho. É preciso esclarecer, porém, que o ponto de vista a partir do qual o Método é aqui tratado é a Educação e o ponto de vista a partir do qual a Educação é tratada, é o Método. Portanto, são de e para educadores as análises da contribuição do Método para a interpretação da realidade apresentadas neste texto.

Karl Marx, alemão, filósofo, economista, jornalista e militante político, viveu em vários países da Europa no século XIX de 1818 a 1883. Na busca de um caminho epistemológico, ou de um caminho que fundamentasse o conhecimento para a interpretação da realidade histórica e social que o desafiava, superou (no sentido de incorporar e ir além) as posições de Hegel no que dizia respeito à dialética e conferiu-lhe um caráter materialista e histórico.

Marx e seu mais constante parceiro intelectual Friedrich Engels (1820-1895), desenvolveram o Método Materialista Histórico Dialético como o caminho epistemológico para fundamentar a interpretação da realidade histórica e social que buscavam compreender: o modo capitalista de produção, então em processo de implantação e desenvolvimento. No entanto, não vamos encontrar uma formulação deste Método, especial, em forma de definição, entre os escritos destes dois pensadores. Encontramos, sim, os seus princípios, os caminhos e as contribuições para sua compreensão no decorrer de suas obras. No entanto, muitos autores indicam que está na Introdução à Crítica da Economia Política (Marx, 1974), manuscrito encontrado em 1902 após sua morte, aquilo que mais se aproxima de uma sistematização do Método. 
Esses apontamentos, publicados, tornaram-se importantes na elaboração, no uso e na precisão das categorias do Método em especial em sua dimensão de instrumento metodológico do estudo da economia política. Temos nessa Introdução apontamentos que serão retomados por Marx em O Capital, de maneira até mais precisa e articulada, mas não expressa como "definição" do Método, mas expresso como o "aplicação" do Método. É na Introdução que encontramos o que se aproxima de uma exposição teórica do método de análise da economia política, de uma crítica à economia política. Além disso, muitos estudos têm sido empreendidos para a identificação e análise do Método, como Kosik (1976); Kopnin (1978); Konder (1981, 1991, 2003); Ianni (1982); Gramsci (1991); entre muitos outros.

O que importa para um Método de interpretação da realidade - no nosso caso, um método de produção de conhecimentos em educação e ensino - é descobrir as leis dos fenômenos de cuja investigação nos ocupamos; importa-nos captar detalhadamente as articulações dos problemas em estudo, analisar as evoluções, rastrear as conexões entre os fenômenos que os determinam e que os envolvem. O Método Materialista Histórico e Dialético nos dá condições de empreender esse movimento.

Uma das primeiras questões que Marx e Engels enfrentaram na elaboração de um novo caminho de interpretação da realidade que buscavam compreender, foi a separação sujeitoobjeto promovida pela lógica formal, então já muito valorizada pela ciência. Buscaram superar essa separação partindo de observações acerca do movimento e da contraditoriedade do mundo, dos homens e de suas relações. Consideremos aqui, como princípio do Método, que a lógica formal não consegue explicar as contradições e nos prende o pensamento impedindo o movimento necessário para a compreensão mais complexa das coisas. Assim, logo chegaram à necessidade de introduzir a dialética no Método que nos orienta a interpretar a realidade.

A dialética, ou mais especificamente, a dialética marxista, surge, portanto, como uma tentativa de superação da dicotomia entre o sujeito e o objeto. No entanto, a dialética surgiu, na história do pensamento humano, muito antes de Marx e Engels. Na Grécia antiga era compreendida como a arte do diálogo, a arte de conversar. Sócrates empregou este conceito para desenvolver sua filosofia e Platão utilizou, abundantemente, a dialética em seus “diálogos". Esses dois pensadores da antiguidade defendiam que a verdade seria atingida pela relação de diálogo que pressupõe minimamente duas instâncias - o eu e o outro. No entanto, é muito importante observar que nessa forma de compreensão, esse diálogo ainda aconteceria sob um princípio de identidade, entre os iguais, eu e outro, mas não contrapostos, não contrários, não contraditórios. Entretanto, essa concepção foi precedida por outra, distinta, 
encontrada principalmente em Heráclito, filósofo grego que viveu de 530 a 428 a.c. Para este, o diálogo somente é possível entre os diferentes. A diferença seria então a própria contrariedade e conflito. Aristóteles veio então com seu princípio de identidade ser um dos grandes responsáveis pela marginalização do pensamento de Heráclito sobre a contraditoriedade e o conflito. Esse princípio da identidade, arguido sistemática e fervorosamente por Aristóteles, era "o que é, é e o que não é, não é". Se em Heráclito encontramos a ideia de movimento do pensamento, a ideia de contraditoriedade da vida, da natureza, do mundo, "todas as coisas fluem e se alteram sempre", e que mesmo na coisa mais imóvel existe um invisível fluxo e movimento (DURANT, 1996), para Aristóteles o mundo e, portanto, o pensamento é o que é, o que parece ser, é.

Essa breve trajetória histórica do conceito de dialética nos mostra que já tínhamos a lógica dialética como uma possibilidade de compreensão da realidade como essencialmente contraditória e em permanente transformação (KONDER, 1981), e, que a lógica dialética é uma contraposição à lógica formal, que não aceita a contradição e o conflito. Se continuarmos nos movimentando pela história da filosofia, bem mais tarde, no Renascimento, identificamos a objetividade do pensamento humano como uma das preocupações centrais, o que implica numa profunda separação entre sujeito e objeto resultando na negação do pensamento dialético como lógica de interpretação do mundo e como objeto de estudo das ciências e da filosofia. No entanto, são muitos os sinais na história do pensamento humano de que a base de compreensão da dialética, - o movimento, a contraditoriedade -, estava presente na elaboração científica de vários pensadores: em Copérnico a terra não é imóvel; em Galileu o movimento é condição natural dos corpos, assim como em Descartes; em Newton “os corpos caem”. Todas essas foram contribuições importantes para a construção da dialética na perspectiva da contradição (KONDER, 1981).

No entanto, é com Hegel (1770-1831), que vamos encontrar a dialética como preocupação filosófica, como objeto de estudo da filosofia. Se Kant (1724-1804) trouxe para a filosofia a ideia da capacidade de intervenção do homem no mundo a partir das reflexões acerca do sujeito ativo, Hegel foi além, tratou da elaboração da dialética como método, desenvolvendo o princípio da contraditoriedade: uma coisa é e não é ao mesmo tempo e sob o mesmo aspecto. Temos aqui, então, uma oposição radical ao dualismo sujeito-objeto e ao princípio da identidade.

Já é muito conhecido o fato de que Marx tomou a dialética de Hegel, invertendo-a, colocando-a na posição, para ele, correta. Isto é, Marx partiu da dialética de Hegel retirando 
seu caráter idealista e ao invertê-la, deu à ela um caráter materialista. Essa ideia, de substituição radical do idealismo pelo materialismo também está presente na famosa Tese XI contra Feuerbach "Os filósofos não fizeram mais que interpretar o mundo de forma diferente; trata-se porém de modificá-lo " Para Marx, Hegel como um idealista, via a razão como determinante da realidade objetiva, enquanto que o mundo, pensava, mostra justamente o contrário: não é a razão humana que determina o mundo, mas é o mundo - material - que condicionava a ideia que fazemos dele. Temos aqui a interpretação da realidade como materialista e dialética.

Portanto, é a dialética de Marx, construção lógica do Método que fundamenta o pensamento marxista e que está aqui apresentada como possibilidade teórica (instrumento lógico) de interpretação da educação, da realidade educacional, que como pesquisadores em educação e ensino queremos compreender da forma mais completa possível.

Assim, avancemos na compreensão de que o Método Materialista Histórico e Dialético desenvolvido por Marx e Engels é Método de interpretação da realidade, visão de mundo e práxis ${ }^{1}$. Eles deram-lhe um caráter material (os homens se organizam em sociedade para a produção e a reprodução da vida) em contraposição ao caráter idealista do que Marx chamou de "os filósofos" na Tese XI contra Feuerbach e histórico (como eles vêm se organizando através dos tempos).

Hoje convivemos com um movimento de crítica, desconsideração - e até ataques - ao pensamento socialista que implica o marxismo. Por conta do desaparecimento no mundo do socialismo real, sistema político, econômico e social fundamentado na também chamada teoria marxista, todo o pensamento marxista, inclusive o Método, tem sido bastante questionado em sua vitalidade, atualidade e, até, na possibilidade de continuar existindo como referencial teórico de compreensão da realidade. Não cabe aqui uma discussão sobre isso, mas vale a pena pontuar que as interpretações marxistas da realidade econômica, social, política e cultural da sociedade organizada sob o modo capitalista de produção foram as interpretações mais completas e originais dessa sociedade - reconhecida por muitos pensadores, inclusive por aqueles que discordaram de suas ideias socialistas de organização social. Nesse sentido, sobrevivendo a sociedade organizada pelo modo capitalista de produção (com todas as suas modificações atuais), sobrevive essa teoria da interpretação. No entanto, uma das tarefas

\footnotetext{
${ }^{1} \mathrm{O}$ conceito de práxis de Marx pode ser entendido como prática articulada à teoria, prática desenvolvida com e através de abstrações do pensamento, como busca de compreensão mais consistente e consequente da atividade prática - é prática eivada de teoria.
} 
daqueles que se dedicam ao estudo do Método, é conferir atualidade e pertinência ao Método Materialista Histórico Dialético, que precisa, é claro, ser constantemente contextualizado, pois uma teoria de interpretação da realidade pela sua própria natureza está sempre em desenvolvimento

O Método Materialista Histórico Dialético caracteriza-se pelo movimento do pensamento pela materialidade histórica da vida dos homens em sociedade, isto é, trata-se de descobrir (pelo movimento do pensamento apoiado no princípio da contradição) as leis fundamentais que definem a forma organizativa (material) dos homens durante a história da humanidade.

O princípio da contradição (a lógica dialética) indica que para pensar a realidade é possível aceitar a contradição, caminhar por ela e apreender o que dela é essencial. Nesse caminho lógico, movimentar o pensamento significa refletir sobre a realidade partindo do empírico (a realidade dada, o real aparente, o objeto assim como se apresenta à primeira vista) e pelas abstrações (elaborações do pensamento, reflexões, teoria, conhecimentos) chegar ao concreto (compreensão mais elaborada do que há de essencial no objeto, concreto pensado). Assim, a diferença entre o empírico (real aparente) e o concreto (real pensado) são as abstrações (reflexões) do pensamento que tornam mais completa a realidade observada (SAVIANI, 1991).

Um outro ponto de fundamental importância para tomarmos o Método como referencial teórico e metodológico para nossos estudos é o que Marx (1974), em seus estudos sobre metodologia da investigação, descobriu como fundamental: a necessidade de definição de uma categoria de análise, tão simples que possa ser tomada imediatamente pelo pesquisador como ponto de partida, e, ao mesmo tempo, tão complexa que possa oferecer as maiores possibilidades de reflexão e análise, para que, de real aparente seja apropriada como real concreto. A essa categoria, Marx chamou de “categoria síntese de múltiplas determinações”. Para Marx, nas análises econômicas de $O$ Capital, a categoria síntese (que proporciona irmos do empírico ao concreto) é a mercadoria, com a qual foi possível partir empiricamente para, pelas abstrações, compreender criticamente a economia do modo capitalista de produção em estudo. Marx (1968) em O Capital apresenta uma imagem que ilustra esta escolha:

Todo começo é difícil em qualquer ciência. Por isso, o capítulo primeiro é o que oferece maior dificuldade à compreensão, notadamente a seção que contém a análise da mercadoria. Nele procurei expor, com a maior clareza possível, o que concerne especialmente à análise da substância e da 
magnitude do valor. A forma do valor, a qual tem no dinheiro sua figura acabada, é muito vazia e simples. Apesar disso, tem o espírito humano, há mais de dois mil anos, tentando em vão devassá-la, embora conseguisse analisar, pelo menos com aproximação, formas muito mais complexas e ricas de conteúdo. Por quê? Porque é mais fácil estudar o organismo, como um todo, do que suas células. Além disso, na análise das formas econômicas, não se pode utilizar nem microscópio nem reagentes químicos. A capacidade de abstração substitui esses meios. A célula econômica da sociedade burguesa é a forma mercadoria, que reveste o produto do trabalho, ou a forma de valor assumida pela mercadoria. Sua análise parece, ao profano, pura maquinação de minuciosidades. Trata-se, realmente, de minuciosidades, mas análogas àquelas da anatomia microscópica. (MARX, 1968, p. 4.)[P1]

É com a preocupação de analisar seu objeto de estudo (a economia política) que Marx encontrou a necessidade de definir um ponto de partida - e de chegada - como síntese de múltiplas determinações, "a mercadoria", buscando movimentar o pensamento pelas contradições que ela implica e revela (dialética), conferindo-lhe um caráter material (os homens se organizam em sociedade para a produção e a reprodução da vida) e histórico (como eles vêm se organizando através dos tempos).

Então, considerar o Método Materialista Histórico e Dialético como instrumento teórico e metodológico para a interpretação da realidade, significa compreender esse processo de interpretação e análise que vai do empírico (realidade aparente, imediata) ao concreto (realidade pensada, compreendida) pelo movimento do pensamento (contradições) no mundo como ele é. Sobre isso, vejamos que

A apreensão teórica pelo investigador do movimento real, prático e efetivo do objeto ou fenômeno investigado, por sua vez, não pode ser realizada de forma imediata. O processo de conhecimento para o materialismo históricodialético não se dá por intermédio do imediatismo do pensamento. $\mathrm{O}$ conhecimento do real não pode se limitar àquilo que é imediatamente dado, pensado ou sentido. Se o pensamento se limita a isso, ele se põe no nível da obviedade, restringe-se a captar o evidente. Além disso, há que se considerar a efetiva distinção entre a aparência e a essência dos processos do real, como assinalou Marx, ao afirmar que se a aparência das coisas se confundisse com sua essência, toda ciência seria supérflua. Dessa maneira é que se pressupõe um caminho de investigação de superação do nível empírico ao nível concreto do real, superação essa que só é possível - para esse método de pesquisa - por meio da análise e da abstração do pensamento do investigador (MARTINS; LAVOURA, 2018).[P2]

Então, se o processo de interpretação da realidade que exige o Método é um processo de captação da essência do real, a investigação da realidade numa sociedade organizada sob o modo capitalista de produção exige que busquemos compreender mais aprofundadamente, em sua interpretação, as contradições em que vivem os sujeitos nesta sociedade. E mais, compreender para quê? Para transformá-la, nos exige Marx na já apresentada Tese XI. 
A riqueza da Tese XI nos obriga a pensar o Método como teoria, mas também e essencialmente como prática, o que encontramos mais comumente abrigada na ideia de práxis. Muito mais do que a teoria como fundamento da prática ou a prática como fundamento da teoria - como parece nos exigir a lógica formal -, a práxis, que é o próprio pensamento de Marx, o próprio "marxismo", ou ainda, o próprio Método Materialista Histórico e Dialético, não é prática humana no sentido pragmático, como também não é uma abstração. Embora muito se tenha discutido sobre o conceito de práxis no marxismo, muitos autores argumentam que práxis é a própria prática. Nesse sentido, as expressões "filosofia da práxis" ou filosofia da prática, trazem o sentido da superação radical do idealismo e do próprio materialismo anterior a Marx. Práxis ou prática, no sentido marxista, é a possibilidade concreta de ação humana plena (VÁZQUEZ, 1968), compreendendo ação humana plena como uma ação prática concreta, pensada, consciente e consistente de tal forma a gestar e concretizar a transformação da realidade.

Práxis, filosofia da práxis, prática, filosofia da prática ou teoria da prática, é no pensamento marxista, a mais radical, original e completa formulação sobre a relação da teoria com a prática. Chama-nos a atenção de que mais do que uma relação entre a teoria e a prática, a práxis é a unidade entre teoria e prática. Essa unidade é tratada por Marx como um problema das relações entre o pensamento e a ação. Segundo Vázquez (1968), Marx considerava que a filosofia não poderia ser um instrumento para justificar a realidade no sentido de sua manutenção, mas não poderia ser também um simples instrumento de crítica a essa realidade: "A filosofia por si mesma, como crítica do real, não muda a realidade. Para mudar a realidade, a filosofia tem que realizar-se" (VÁZQUEZ, 1968, p. 125). O papel da filosofia se realiza pela práxis: a transformação da filosofia em prática e da prática em filosofia, isto é, a teoria tornase prática quando concretamente presente na consciência dos homens, e a prática torna-se teoria quando dá sentido ao pensamento humano. Práxis é, portanto, a unidade teoria, prática e transformação social.

Então, é para a vida real que voltamos todos os esforços de interpretação da realidade, é para contribuir na transformação da realidade condicionada pelo modo capitalista de produção que nos dedicamos a estudar o fenômeno educativo, mas, isso somente é possível se compreendermos - material, histórica e dialeticamente - nossos objetivos de estudo. 


\section{A Pesquisa em Educação}

Ao abordarmos a pesquisa em educação para pensarmos no Método Materialista Histórico e Dialético nesta perspectiva, destaca-se o conhecimento da realidade para transformação das condições históricas e sociais, o processo de produção do conhecimento sobre a realidade para transformá-la. Nossa principal preocupação aqui é a produção do conhecimento sobre educação.

Pensemos, então, nas três dimensões do "conhecimento": como um mecanismo de compreensão e transformação do mundo, como uma necessidade para a ação e, ainda, como um elemento de libertação (LUCKESI, 2012).

O conhecimento como um mecanismo de compreensão e transformação do mundo, segundo esse autor, nos remete à reflexão sobre nosso mundo cultural. O mundo humano é um mundo construído pela cultura, pelos sujeitos humanos em sua relação entre si e deles com o ambiente em que vivem. Vivemos no mundo em constante atividade: observamos, sentimos, agimos e pensamos. Todos os nossos atos são acompanhados de pensamento, de reflexões sobre o observado, o sentido e o vivido. Então, necessitamos, além de viver no mundo, pensálo, compreendê-lo, isto é, conhecê-lo. Essa ação diferenciada de pensar o mundo e suas coisas é o movimento humano de dar significado a tudo, de compreender da forma mais aprofundada possível nossas relações com o mundo e com as coisas: "temos como pressupostos básicos que o conhecimento só nasce da prática com o mundo, enfrentando os seus desafios e resistências e que o conhecimento só tem seu sentido pleno na relação com a realidade" (LUCKESI, 2012, p. 49).

Assim, o conhecimento torna-se a compreensão teórica do mundo e das coisas, a elaboração deles no pensamento, a busca de significado para eles, no pensamento, mas tornase também a ação prática, a definição, no pensamento e na ação, do modo de agir sobre o mundo compreendido, significado:

O conhecimento é uma capacidade disponível em nós, seres humanos, para que processemos de forma mais adequada a nossa vida, com menos riscos e menos perigos. O conhecimento tem o poder de transformar a opacidade da realidade em caminhos "iluminados", de tal forma que nos permite agir com certeza, segurança e previsão (LUCKESI, 2012, p. 51).[P3]

Neste sentido, buscamos conhecer, significar, compreender, em todas as situações vividas: desde uma simples ação cotidiana como tomar um banho ou cozinhar uma refeição até as mais sofisticadas ações realizadas por complicadas operações e procedimentos científicos em busca de desvendar mistérios sobre o funcionamento da vida em suas mais 
diversas dimensões. Todo conhecimento tem como objetivo, pois, a convivência dos sujeitos com o mundo e as coisas que o cercam, uma convivência compreendida, significada. Agir sobre o mundo para transformá-lo, ação humana por excelência, exige sua compreensão, sua interpretação. Então, a busca do conhecimento é uma atitude essencialmente humana, isto é, buscar compreender e dar significado para o mundo e as coisas é uma atitude essencialmente humana.

Pensemos ainda que o processo de elaboração de conhecimento sobre o mundo não é um processo individual. Os significados produzidos para sua compreensão foram e são produzidos durante toda história da humanidade pelo conjunto dos sujeitos sociais. Isso significa dizer que o conhecimento é histórico e social. Histórico porque cada conhecimento novo é um aprofundamento de conhecimentos anteriores; e é social porque nenhum sujeito constrói um conhecimento totalmente novo: todo conhecimento apoia-se em conhecimentos anteriores, produzidos por outros sujeitos. Portanto, o conhecimento "novo" é também socialmente produzido.

Além de um mecanismo de compreensão do mundo como acabamos de ver, o conhecimento é uma necessidade para a ação. Além de diferenciar os sujeitos de outras espécies, pela possibilidade de compreender o mundo através do pensamento, o conhecimento fundamenta a ação sobre o mundo, isto é, ele apresenta-se como uma necessidade para dar às ações humanas uma de suas principais características, a intencionalidade. Se a ação humana sobre o mundo e as coisas é uma ação intencional, dirigir conscientemente a ação significa conhecer, compreender seus múltiplos aspectos. O conhecimento "ilumina" a ação humana sobre o mundo e as coisas, é a luz do caminho a ser percorrido. Agir e sentir pensando e compreendendo é uma característica essencialmente humana, portanto, é impossível nos relacionarmos com o mundo sem um "ajuste" cognitivo sobre a realidade que nos cerca, isto é, não conseguimos viver sem compreender o mundo que nos rodeia. Esse "ajuste cognitivo" é a busca do conhecimento, dos instrumentos necessários para dar direção às nossas ações, para nos dar segurança, compreendendo o caminho ao caminhar.

O conhecimento pode ser também um instrumento de libertação. Mas, lembremos que, assim como o conhecimento pode ser libertador, ele pode ser opressor. Isto é, o conhecimento não é neutro. Se o conhecimento é um construto humano, se ele é histórico e social, ele pode estar a serviço da libertação dos sujeitos ou a serviço de sua opressão, de seu controle. Somente quando o conhecimento atua de acordo com as necessidades e vontades de todos os sujeitos envolvidos em seu processo ele é libertador. Quando o conhecimento atua a serviço de 
determinados grupos com o objetivo de defender seus interesses em detrimento dos interesses dos outros ele é um instrumento de controle, de opressão.

O conhecimento, portanto, é uma forma teórico-prática de compreensão do mundo, dos homens e das coisas, um instrumento para o entendimento das relações dos sujeitos entre si e deles com o ambiente em que vivem, em variadas, múltiplas e detalhadas dimensões.

Se o conhecimento é o instrumento central da concretização dos seres humanos como humanos, instrumentaliza-os para a pensar e agir mais conscientemente sobre o mundo; sua prática social, a pesquisa, é uma atividade complexa que se realiza em todos os momentos da vida humana. Isso tudo nos leva a concluir que pesquisar é produzir conhecimentos para a ação. Nossa atividade como educadores, na qual o conhecimento ocupa um papel de destaque, exige que tratemos mais do conhecimento - e de sua produção - de forma mais sistematizada. No mundo acadêmico, em particular, nos dedicamos a uma prática de pesquisa bastante sistematizada, mais organizada, para que a produção dos conhecimentos necessários às formas científicas de compreensão da realidade possam resultar em conhecimentos elaborados e sistematizados ao alcance de todos os pesquisadores.

Neste sentido, é para a produção de conhecimentos, dos conhecimentos sobre a educação e o ensino, que trago neste texto algumas das possibilidades teóricas e metodológicas do Método Materialista Histórico e Dialético. Saviani (1991), discutindo a necessidade de o educador brasileiro passar do senso comum para a consciência filosófica na compreensão de sua prática educativa. O Método, como instrumento desta prática, implica na superação da etapa de senso comum educacional (conhecimento da realidade empírica da educação), e, por meio da reflexão teórica (movimento do pensamento, abstrações), atingir a etapa da consciência filosófica (realidade concreta da educação, concreta pensada, realidade educacional plenamente compreendida). Sobre estas questões, escreve:

Com efeito, a lógica dialética não é outra coisa senão o processo de construção do concreto de pensamento (ela é uma lógica concreta) ao passo que a lógica formal é o processo de construção da forma de pensamento (ela é, assim, uma lógica abstrata). Por aí, pode-se compreender o que significa dizer que a lógica dialética supera por inclusão/incorporação a lógica formal (incorporação, isto quer dizer que a lógica formal já não é tal e sim parte integrante da lógica dialética). Com efeito, o acesso ao concreto não se dá sem a mediação do abstrato (mediação da análise como escrevi em outro lugar ou "detour" de que fala Kosik). Assim, aquilo que é chamado lógica formal ganha um significado novo e deixa de ser a lógica para se converter num momento da lógica dialética. A construção do pensamento se daria pois da seguinte forma: parte-se do empírico, passa-se pelo abstrato e chega-se ao concreto (SAVIANI, 1991, p. 11). [P4] 
Assim, temos que uma grande contribuição do Método para os educadores, como auxílio na tarefa de compreender o fenômeno educativo, diz respeito à necessidade lógica de descobrir, nos fenômenos, a categoria síntese (empírica) para chegar à categoria síntese (concreto pensado). Isto significa dizer que a análise do fenômeno educacional em estudo pode ser empreendida quando conseguimos descobrir sua mais simples manifestação para que, ao nos debruçarmos sobre ela instrumentalizando-nos com o conhecimento já produzido e pensado em suas três dimensões, elaborando abstrações, possamos compreender plenamente o fenômeno observado. Assim pode, por exemplo, um determinado processo educativo ser compreendido a partir das reflexões empreendidas sobre as relações cotidianas entre professores e alunos na sala de aula. Quanto mais abstrações (teoria, conhecimento) pudermos pensar sobre esta categoria simples, empírica (relação professor/aluno), mais próximo estaremos da compreensão plena do processo educacional em questão. Se a lógica dialética permite e exige o movimento do pensamento, a materialidade histórica diz respeito à forma de organização dos homens em sociedade através dos tempos, isto é, diz respeito às relações sociais construídas pela humanidade durante todos os séculos de sua existência.

Para o pensamento marxista esta materialidade histórica pode ser compreendida a partir das análises empreendidas sobre uma categoria considerada central: o trabalho. E por que o trabalho? Em primeiro lugar, é preciso considerar que o conceito de trabalho em Marx não se esgota no conceito cotidiano de trabalho, na concepção do senso comum de trabalho que se aproxima da ideia de ocupação, tarefa, um conceito puramente econômico. O conceito de trabalho, categoria central nas relações sociais, para o pensamento marxista é o conceito filosófico de trabalho, é a forma mais ampla e complexa de se pensar o trabalho.

Nas análises marxistas acerca desta questão, de caráter mais filosófico do que econômico, encontramos que o trabalho é central nas relações dos homens com a natureza e com os outros homens porque esta é sua atividade vital. Isto quer dizer que, se o caráter de uma espécie define-se pelo tipo de atividade que ela exerce para produzir ou reproduzir a vida, esta atividade vital, essencial nos homens, é o trabalho - a atividade pela qual ele garante sua sobrevivência e por meio da qual a humanidade conseguiu produzir e reproduzir a vida humana (MARX, 1974). Hoje se discute a centralidade da categoria trabalho no mundo contemporâneo. As modificações das relações de trabalho teriam, segundo algumas teses, levado o trabalho a perder a característica de estruturação das relações sociais. No entanto, parece que as modificações no mundo do trabalho não significam transformações profundas nas relações sociais, especialmente nas relações sociais sob o modo capitalista de produção 
(ANTUNES, 2013). Assim, o trabalho é categoria central de análise da materialidade histórica dos homens porque é a forma mais simples, mais objetiva, que eles desenvolveram para se organizarem em sociedade. A base das relações sociais são as relações sociais de produção, as formas organizativas do trabalho. Ocorre que, na sociedade sob o modo capitalista de produção, o trabalho (atividade vital, essencial) é explorado (comprado por um preço sempre menor do que produz) definindo, assim, um processo de alienação (expropriação da atividade essencial em sua plenitude). Se o trabalho, como atividade essencial e vital traz a possibilidade de realização plena do homem enquanto tal (humanização), a exploração do trabalho determina um processo inverso: a alienação. Sob a exploração do trabalho, os homens tornamse menos homens, há uma quebra na possibilidade de, pelo trabalho, promover a humanização dos homens.

Este movimento contraditório humanização/alienação é fundamental para a educação e para a organização do processo educacional. A educação estará, em suas várias dimensões, "a serviço" da humanização ou da alienação? Esta pergunta tem que ser respondida pelos educadores e pelos pesquisadores em educação e ensino como direção de sua prática educativa e investigativa.

É nesta contradição que podemos buscar, em nossos estudos, nosso ponto de partida e de chegada - para as reflexões e análises. Não há possibilidade de construção de um agir pedagógico - no ensino e na pesquisa - sem que esta questão esteja presente. Há, sim, possibilidade de estar escondida, camuflada, não pensada, mas estará sempre presente. $\mathrm{O}$ conhecimento, como instrumento particular do processo educacional, pode ser tratado de forma a contribuir ou a negar o processo de humanização. Se retomarmos a definição de Saviani (1994, p. 24) de que a educação é "o ato de produzir, em cada indivíduo singular, a humanidade que é produzida histórica e coletivamente pelo conjunto dos homens", vemos que aqui ele trata da produção histórica e coletiva da humanidade, isto é, trata do conjunto de instrumentos (objetos, ideias, conhecimento, tecnologia etc) com os quais os homens se relacionam com a natureza e com os outros homens para promover a sobrevivência. Se a forma histórica de produzir a humanidade chama-se trabalho, portanto a centralidade do trabalho nas relações sociais diz respeito também à educação. Muitos autores vêm discutindo as relações entre trabalho e educação, inspirados, principalmente, pelos escritos de Antônio Gramsci, importante marxista italiano que viveu entre 1891 e 1926. No Brasil, foi na década de 80 do século XX que a relação entre trabalho e educação tornou-se objeto de estudos em programas de pós-graduação em Educação e Ensino. Os mais importantes pesquisadores sobre esse tema 
desde então têm sido, entre outros, Miguel Arroyo, Maria Julieta Costa Calazans, Gaudêncio Frigotto, Carlos Minayo, Paolo Nosella, Ramon Pena Castro, Acácia Kuenzer, Celso J. Ferretti, Maria Ciavatta Franco e Eunice Trein (FRIGOTTO; FRANCO, 1997). Também é importante registrar que o italiano Mário Manacorda e o espanhol Mariano Enguita são importantes referencias neste tema. Todos esses autores apontam, com diferentes termos que, para que a educação seja um instrumento do processo de humanização, o trabalho deve aparecer como princípio educativo. Isto quer dizer que a educação não pode estar voltada para o trabalho de forma a responder às necessidades adaptativas, funcionais, de treinamento e domesticação do trabalhador, exigidas em diferentes graus, pelo mundo do trabalho em nossas sociedades, mas sim que a educação pode ter como preocupação fundamental o trabalho em sua forma mais ampla. Analisar o processo educacional a partir de reflexões empírico-teóricas para compreendê-lo em sua concretude, significa refletir sobre as contradições da organização do trabalho em nossa sociedade, sobre as possibilidades de superação de suas condições adversas e empreender, no interior do processo educativo, ações que contribuam para a humanização plena do conjunto dos homens em sociedade.

Considerando que os homens se caracterizam por um permanente vir a ser, a relação entre os homens não está dada, mas precisa ser construída (vir a ser), construída material (trabalho social) e historicamente (organização social do trabalho). O trabalho, como princípio educativo, traz para a educação a tarefa de educar pelo trabalho e não para o trabalho, isto é, para o trabalho amplo, filosófico, trabalho que se expressa na práxis (articulação da dimensão prática com a dimensão teórica, pensada).

\section{Conclusão}

Como contribuição do Método à Educação é importante destacar que o processo educacional é amplo e complexo, não se esgota na dimensão prática nem na teórica, exige a construção da formação em sua totalidade, tem que contribuir para a formação de homens plenos, plenos de humanidade. É com relação a estas questões que a discussão sobre o Método Materialista Histórico e Dialético como referencial teórico e metodológico para a pesquisa em Educação pode contribuir. Trata-se de refletir sobre o desafio de superar a lógica formal da ciência moderna nas relações educativas desta área, lógica que, em última análise, separa sujeito e objeto no processo educativo. A construção de ações mais filosóficas, mais pensadas, mais completas, mais cheias de movimento dialético, permitirá que o agir pedagógico tornese mais relacionado à realidade concreta. 
A apresentação do Método aqui teve como objetivo contribuir para que nos apropriemos de um instrumental metodológico que nos possibilite análises desta realidade concreta (histórica e material), ou seja, que o Método possa contribuir para que cada educador/pesquisador construa sua prática por meio da compreensão mais ampla da realidade. A intenção deste processo de reflexão, portanto, foi contribuir para que percebamos o princípio da contraditoriedade da realidade histórica de suas relações nesta sociedade: a alienação e seu contrário, a humanização dos homens. E, que isto aconteça não apenas para constatação da situação histórica, mas, principalmente, para que cada um possa, de alguma maneira, contribuir para sua superação. O maior desafio que o Método coloca é permitir e até exigir que, na ação cotidiana, o pensamento faça movimentos lógico-dialéticos na interpretação da realidade, com o objetivo de compreendê-la para transformá-la. Assim, se "os filósofos se limitaram a interpretar o mundo de diferentes maneiras; o que importa é transformá-lo" - Tese XI sobre Feuerbach (MARX; ENGELS, 1963).

\section{Referências}

ANTUNES, R. Os sentidos do trabalho: ensaio sobre a afirmação e negação do trabalho. Coimbra: CES/Almedina, 2013.

DURANT, W. História da Filosofia. São Paulo: Nova Cultural, 1996. (Os Pensadores). FRIGOTTO, G.; FRANCO, M. C. Informes dos Núcleos: os núcleos de estudos sobre trabalho e educação no Brasil. Trabalho \& Educação, Belo Horizonte, n. 1, p. 160-73, fev./jul. 1997.

GRAMSCI, A. A concepção dialética da história. Rio de Janeiro: Civilização Brasileira, 1991.

IANNI, O. Dialética \& capitalismo: ensaio sobre o pensamento de Marx. Petrópolis: Vozes, 1982.

KONDER, L. A dialética e o marxismo. Trabalho Necessário, Niterói, v. 1, n. 1, p. 1-10, 2003.

KONDER, L. Hegel, a razão quase enlouquecida. Rio de Janeiro: Campus, 1991.

KONDER, L. O que é dialética. São Paulo: Brasiliense, Primeiros Passos, 1981.

KOPNIN, P. V. A dialética como lógica e teoria do conhecimento. Rio de Janeiro:

Civilização Brasileira, 1978.

KOSIK, K. Dialética do concreto. Rio de Janeiro: Paz e Terra, 1976.

LUCKESI, C.C. Fazer Universidade: uma proposta metodológica. São Paulo: Cortez, 17ed, 2012. 
MARTINS, L. M.; LAVOURA, T. N. Materialismo histórico-dialético: contributos para a investigação em educação. Educar em Revista, Curitiba, v. 34, n. 71, p. 223-239, 2018.

MARX, K. Introdução à crítica da economia política. In: MARX, K. Manuscritos econômico - filosóficos e outros textos escolhidos. São Paulo: Abril Cultural, 1974. v. 35, p. 107-138. (Os Pensadores).

MARX, K. O Capital: crítica da economia política. Rio de Janeiro: Civilização Brasileira, 1968.

MARX, K.; ENGELS, F. Obras escolhidas. Rio de Janeiro: Editorial Vitória Limitada, 1963. p. 208-210.

SAVIANI, D. Introdução. In: SAVIANI, D. Educação: do senso comum à consciência filosófica. São Paulo: Cortez, 1991.

SAVIANI, D. Pedagogia histórico crítica: primeiras aproximações. São Paulo: Autores Associados, 1994.

VÁSQUEZ, A. S. Filosofia da Práxis. Rio de Janeiro: Paz e Terra, 1968.

\title{
THE HISTORICAL AND DIALETIC MATERIALIST METHOD FOR EDUCATION RESEARCH
}

\begin{abstract}
This article presents the Historical and Dialectical Materialist Method as a possible approach to interpret social reality, and, consequently, the educational reality. The logical construction of this Method, which substantiates the Marxist thought, presents itself as a theoretical (logical instrument) and methodological (guiding pathways) possibility to interpret reality. This methodological perspective is distinguished by the movement of thought through the historical reality of men's life in society, i.e., it deals with discovering (by the movement of thought) the fundamental laws that define the organizational way that humankind has historically framed its social groups. This instrument of theoretical and practical reflection can be used by educators to analyze the apparent educational reality to fully comprehend and overcome it, turning it into an interpreted and concrete educational reality, and unveiling its varied and contradictory aspects. This movement could lead to more conscious and consequent political choices and the transformation of this reality.
\end{abstract}

Keywords: education; Marxism; theoretical models 